\title{
AVALIAÇÃO DO DESPERDÍCIO DE ALIMENTOS NA DISTRIBUIÇÃO DO ALMOÇO SERVIDO PARA ESTUDANTES DE UM COLÉGIO PRIVADO EM SÃO PAULO, SP
}

\author{
EVALUATION OF FOOD WASTE IN THE DISTRIBUTION OF LUNCH SERVED TO \\ STUDENTS OF A PRIVATE SCHOOL IN SAO PAULO, BRAZIL
}

\author{
Cilea Pikelaizen ${ }^{1}$ \\ Mônica Glória Neumann Spinelli²
}

RESUMO: Na área de alimentação, o desperdício pode ser observado dentro dos cestos de lixo e no retorno das bandejas de refeição. O controle de resto avalia a adequação da quantidade preparada em relação às necessidades, à porção distribuída e à aceitação do cardápio. Nesse contexto, o objetivo foi avaliar o desperdício de alimentos de uma UAN em uma escola privada em São Paulo por meio do percentual de restos e sobras. $A$ unidade estudada atende, no almoço, em média, 70 estudantes com idade entre 1 e 10 anos. Para avaliar o desperdício, foram pesados os restos e as sobras do balcão de distribuição. Após os cálculos, pôde-se fazer uma avaliação do desperdício da UAN estudada. A média do consumo per capita foi de 207,9 gramas $( \pm 28,6)$ e a média de sobras foi de $28,6 \%( \pm 4,2)$, valores superiores ao preconizado como índice adequado. $A$ média de restos dos 5 dias foi de 21,1\% ( $\pm 3,2)$, valor acima do recomendado. Sugere-se a implantação de medidas educativas, estipulação de metas de desperdício e uma melhor organização na distribuição das preparações dos cardápios, contribuindo para aumento do consumo e menor desperdício.

Palavras-chave: desperdício; consumo; estudantes.

ABSTRACT: At food services, waste can be observed in the garbage can and the return of meal trays. Waste control assesses the appropriateness of the amount prepared in relation to the needs, distributed portion, and acceptance of the menu. In this context, the objective was to evaluate food waste of a Unit of Food and Nutrition in a private school in Sao Paulo by the percentage of remnants and leftovers. At lunch, the studied unit serves an average of 70 students between 1 and 10 years old. To evaluate the waste, the remains and leftovers of the food from the distribution counter were weighed. After calculations, we could assess the waste of the canteen. The average per capita of consumption was 207.9 grams ( \pm 28.6 ). The leftover average was $28.6 \%$ ( \pm 4.2$)$ higher than the recommended values of the appropriate index. The average leftovers from 5 days were $21.1 \%( \pm 3.2)$ above the recommended value. We suggest the implementation of educational measures, stipulated targets of waste, and better organization of distribution in the preparations of menus to help increase consumption and produce less waste.

Keywords: waste; consumption; students.

\footnotetext{
${ }^{1}$ Graduada em Nutrição - Universidade Presbiteriana Mackenzie - UPM. E-mail: cileapm@hotmail.com.

${ }^{2}$ Doutora em Saúde Pública - Universidade de São Paulo - USP e Docente da UPM. E-mail: monicaspi404@gmail.com.
} 


\section{INTRODUÇÃO}

Uma Unidade de Alimentação e Nutrição (UAN) consiste de um serviço organizado, com o objetivo de fornecer refeições balanceadas dentro dos padrões dietéticos e higiênicos, visando, assim, atender às necessidades nutricionais de seus clientes, de forma que esteja ajustado aos limites financeiros da instituição (ABREU; SPINELLI; SOUZA PINTO, 2011). Uma UAN sempre deve visar à melhoria dos serviços prestados, por meio de um conhecimento aprofundado dos processos executados, de um planejamento competente e da disseminação do conceito de alimentação saudável (AKUTSU et al., 2005).

$\mathrm{Na}$ área de alimentação, o desperdício pode ser observado dentro dos cestos de lixo e no retorno das bandejas de refeição (BRADACZ, 2003). Diante disso, percebe-se que os alimentos são, literamente, jogados no lixo, além do desperdício estar incorporado à nossa cultura (AKUTSU et al., 2005).

Segundo cálculos realizados pela Secretaria da Agricultura e Abastecimento de São Paulo, o Brasil possui um alto índice de desperdício de alimentos, já que são jogados no lixo o equivalente a $R \$ 12$ bilhões em alimentos por ano, e essa quantia seria suficiente para alimentar cerca de 30 milhões de pessoas ou oito milhões de famílias durante um ano (MULLER, 2008).

O índice de resto é um indicativo de desperdício que avalia quando $o$ alimento foi servido, mas não consumido. É definido como a quantidade de alimentos devolvida no prato ou bandeja pelo cliente ou comensal. O percentual de resto representa a quantidade desses alimentos em relação à quantidade produzida (VAZ, 2006).
O controle de desperdícios tem por objetivo avaliar a adequação das quantidades preparadas em relação às necessidades de consumo (sobra), ao porcionamento na distribuição e à aceitação do cardápio (resto). Embora alguns autores considerem que o resto deva ser muito próximo do zero (ABREU; SPINELLI; SOUZA PINTO, 2011), outros, como Maistro (2000), consideram como sendo percentuais de resto aceitáveis taxas inferiores a $10 \%$.

Nesse contexto, o objetivo desta pesquisa foi avaliar $\mathrm{O}$ desperdício de alimentos de uma UAN em uma escola privada em São Paulo-SP, por meio do percentual de restos e sobras.

\section{METODOLOGIA}

Esta pesquisa foi desenvolvida em uma Unidade de Alimentação e Nutrição de uma escola privada, na cidade de São Paulo, SP. O refeitório atende estudantes com idade entre 1 e 10 anos, sendo que as crianças menores são servidas por uma funcionária da instituição e as maiores se servem sozinhas com 0 auxílio da funcionária. A unidade atende, em média, 70 refeições, no horário do almoço, de segunda a sexta. No cardápio, são disponibilizados, uma opção de carne, um acompanhamento, arroz, feijão, dois tipos de salada e sobremesa.

Para avaliar o desperdício, foram pesados, durante 5 dias não consecutivos, os restos do almoço, por meio de uma balança digital Toledo®, com capacidade de $15 \mathrm{~kg}$. Para a obtenção do peso da refeição distribuída, foi feita a pesagem de cada cuba de cada preparação, depois de pronta, e descontado o valor do recipiente. Os valores obtidos foram somados, resultando no total 
de alimentos distribuídos. Desse total, foi diminuído o peso das sobras, mensurado após a distribuição das refeições, para obtenção do total de alimentos consumidos no almoço.

Os materiais não comestíveis, como casca de frutas e descartáveis em geral, foram descartados em sacos para lixo diferenciados dos alimentos.

Os ossos foram separados dos restos e pesados separadamente. A partir do peso dos ossos, foi calculada a porcentagem de seu peso em relação ao total distribuído (33,4\% no $2^{\circ}$ dia e $35,7 \%$ no $4^{\circ}$ dia). No final, esse valor foi descontado do peso da refeição distribuída, consumida e das sobras.

As sobras consideradas foram as que restaram no balcão de distribuição. $O$ peso das sobras foi obtido por meio da pesagem dos alimentos que ficaram no balcão de distribuição. Por fim, foi feito o cálculo de porcentagem de sobras (ABREU; SPINELLI;
SOUZA PINTO, 2011).

Obteve-se o peso do resto por meio da pesagem da lixeira onde estavam os alimentos coletados na área de devolução das bandejas e utensílios, descontando-se o peso destes.

O índice de Resto (IR) foi calculado, de acordo com Abreu, Spinelli e Souza Pinto (2011), dividindo-se o peso da refeição rejeitada pelo peso da refeição distribuída, e transformando-se em percentual.

Para calcular o resto per capita, obteve-se o valor do resto e dividiu-se pelo número de refeições servidas. Após os cálculos, pôde-se fazer uma avaliação do desperdício da UAN estudada.

\section{RESULTADOS E DISCUSSÃO}

Os resultados obtidos, nos 5 dias de coleta do almoço, estão representados em tabelas, e apresentam médias, desvios padrões, e percentuais.

Tabela 1 - Peso de alimentos distribuídos, consumidos e sobras. São Paulo, 2012.

\begin{tabular}{ccccc}
\hline Dia & $\begin{array}{c}\text { Alimentos } \\
\text { distribuídos(g) }\end{array}$ & $\begin{array}{c}\text { Alimentos } \\
\text { consumidos }(\mathbf{g})\end{array}$ & Sobras $(\mathbf{g})$ & Sobras (\%) \\
\hline 1 & 20392 & 15842 & 9406 & 31,6 \\
2 & 16641 & 12391 & 7947 & 32,3 \\
3 & 14796 & 11966 & 5522 & 27,2 \\
4 & 18386 & 14396 & 5144 & 21,9 \\
5 & 16062 & 13314 & 6958 & 30,2 \\
\hline Média & 17255,4 & 13581,8 & 6995,4 & 28,6 \\
Desvpad & 2177,5 & 1571,0 & 1754,7 & 4,2 \\
\hline
\end{tabular}

A Tabela 1 apresenta o total de alimentos distribuídos, consumidos e sobras do almoço nos 5 dias pesquisados. A partir desses dados, encontrou-se uma média do consumo per capita de 207,9 gramas $( \pm 28,6)$.
Em estudo feito por Amorim e Gatti (2010), que avaliaram índice de restos e sobras em uma UAN de uma escola estadual em Guarupuava-PR, foi encontrada uma média do consumo per capita dos alimentos de 637,84 gramas. A média de 
consumo alimentar, provavelmente, foi superior devido ao fato do grupo alvo da UAN da escola estadual ser constituído, na maioria, por adolescentes e a deste estudo ser de pré-escolares e escolares do ensino fundamental.

A média de sobras foi de $28,6 \%( \pm 4,2)$, valores superiores ao preconizado como índice adequado para indicar aceitabilidade da refeição, que, segundo Vaz (2006), é de até $3 \%$. As sobras per capita apresentaram uma média de 107,0 gramas $( \pm 25,9)$.

O resultado da porcentagem de sobras se assemelha ao encontrado por Amorim e Gatti (2010), que, em seu estudo, identificaram uma média de $32,18 \%$. Já, as sobras per capita deste estudo apresentaram valor menor do encontrado na escola estadual (205,29 gramas). Segundo Amorim e Gatti (2010), o alto percentual de sobras de almoço, do seu estudo, pode ser provavelmente justificado, pois era produzida, intencionalmente, uma quantidade excedente de alimentos, para serem oferecidos no jantar, em função do número insuficiente de funcionários para $o$ seu preparo.

No caso da unidade estudada, podem ter contribuído, com a quantidade de sobras, a grande variabilidade do número de comensais, pois o número de alunos que ficam integralmente na escola varia de acordo com $o$ dia $e$ a atividade extracurricular praticada por criança. No caso dos dias estudados, o número de alunos variou de 52 a 76 crianças.
Os dias que apresentaram maior porcentagem de sobras foram $01^{\circ}, 2^{\circ}$ e $5^{\circ}$. Podem ter influenciado, nos altos índices de sobras, o cardápio do $1^{\circ}$ dia, que ofereceu seleta de legumes fria (cenoura, batata e vagem) com $72,3 \%$ de sobras e no $2^{\circ}$ dia foi servido, como acompanhamento, legumes cozidos (cenoura, batata e ervilha) com $58,4 \%$ de sobras. De forma geral, legumes cozidos não apresentaram boa aceitação entre as crianças, e servir preparações muito parecidas em dias seguidos pode ter colaborado com o aumento da rejeição desses alimentos.

Segundo Abreu, Spinelli e Souza Pinto (2011), não existe uma porcentagem ideal de sobras, cada unidade deverá medir ao longo do tempo, para, assim, estabelecer um parâmetro próprio. A avaliação das sobras servirá para medir a eficiência do planejamento e da produção de alimentos, em que valores muito altos podem significar: preparações incompatíveis com o hábito alimentar ou padrão do cliente, falha na determinação do número de refeições e da quantidade per capita, má aparência ou má apresentação dos alimentos e falhas no porcionamento na hora da distribuição.

Para o melhor controle de sobras, algumas medidas podem ser tomadas, como: elaboração de cardápios que satisfaçam a população atendida e treinamento e conscientização da equipe para fazer as preparações em quantidades adequadas (VAZ, 2006). 
Tabela 2 - Peso de alimentos distribuídos, consumidos e restos. São Paulo, 2012.

\begin{tabular}{ccccc}
\hline Dia & $\begin{array}{c}\text { Alimentos } \\
\text { distribuídos(g) }\end{array}$ & $\begin{array}{c}\text { Alimentos } \\
\text { consumidos }(\mathbf{g})\end{array}$ & Restos (g) & Restos (\%) \\
\hline 1 & 20392 & 15842 & 4550 & 22,3 \\
2 & 16641 & 12391 & 4250 & 25,5 \\
3 & 14796 & 11966 & 2830 & 19,1 \\
4 & 18386 & 14396 & 3990 & 21,7 \\
5 & 16062 & 13314 & 2748 & 17,1 \\
\hline Média & 17255,4 & 13581,8 & 3673,6 & 21,1 \\
Desvpad & 2177,5 & 1571,0 & 832,0 & 3,2 \\
\hline
\end{tabular}

A Tabela 2 apresenta 0 total de alimentos distribuídos, consumidos e restos do almoço nos 5 dias pesquisados. A média de restos dos 5 dias foi de $21,1 \%( \pm 3,2)$, valor acima do recomendado por Castro et al. (2003), que é de taxas inferiores a 10\% em coletividades sadias, acima disso pressupõe-se que os cardápios estão inadequados, por serem mal planejados ou mal executados.

Os restos per capita tiveram uma média de 55,3 gramas $( \pm 6,6)$, valor menor do que o encontrado por Amorim e Gatti (2010), com média de resto per capita de 85 gramas.

Resultado parecido do percentual de restos foi encontrado por Faquim, Oliveira, Spinelli (2012), que avaliaram o porcionamento, consumo e desperdícios em um restaurante escolar, encontrando porcentagens de restos muito altas, variando entre 22,6 e $47,1 \%$. Provavelmente, isso ocorra, pois, diferente dos serviços que atendem adultos, na escola uma boa parte dos pratos é porcionada por adultos e não pelas crianças.

Estudo feito por Campos, Viana e Rocha (2011), sobre desperdício alimentar no meio escolar, acharam como média de índice de resto, $31 \%$. Valores muito maiores do que os preconizados, e que, possivelmente, denotam uma ingestão menor do que a recomendada, uma vez que os cardápios são elaborados de forma a se adequar à necessidade energética dos alunos.

O percentual elevado de resto deste estudo pode ter ocorrido devido ao cardápio, oferecido nos dias da coleta, ser composto de preparações de carne cozida (dias 1, 3 e 5) e frango assado (2 e 4).

O dia 2 foi o que apresentou maior porcentagem de restos (25,5\%); nesse dia, foi servido frango, essa preparação estava dura e passada do ponto, isso, provavelmente, pode ter ocorrido pela má manutenção e desgaste dos equipamentos. Considerando que a apresentação visual é importante para a escolha dos alimentos, esse fato pode ter favorecido a diminuição da aceitação desse prato e, assim, o aumento dos restos.

No segundo dia, houve, ainda, a distribuição de picolés como sobremesa, o que pode ter levado ao aumento de desperdício nesse dia, em relação aos outros dias, pois muitas crianças deixaram de comer toda a comida oferecida para ganhar antes o picolé.

Os dias 1 e 4 também apresentaram porcentagens altas de restos, 22,3\% e $21,7 \%$, respectivamente. No $1^{\circ}$ dia, em que 
foi servida carne cozida com cenoura, observou-se que a carne cozida, quando adicionada de legumes, não foi apreciada pelos comensais, resultando em um grande desperdício.

No dia 4, foi novamente servido frango assado, o que pode ter contribuído para a alta porcentagem de restos. A repetição de frango somou-se ao serviço de beterraba como salada, que apresentou uma alta quantidade de sobras (57\%), por não ser muito bem aceita pelas crianças, aumentando, assim, o desperdício.

Os altos valores de restos e sobras podem significar um preocupante problema de aceitação das preparações. Quando se trabalha com crianças, é importante atentar aos seus hábitos alimentares e à aparência ou apresentação dos alimentos, uma vez que a criança é muito seletiva nas suas escolhas.

Quando distribuídos, os alimentos ficam dispostos na pista de distribuição, em cubas de inox (gastronorms), não sendo priorizada a apresentação. A maior parte das crianças já recusa o alimento antes mesmo de ir para o prato, aumentando, assim, a porcentagem de sobras.

Outro fator importante nos índices de desperdício é a qualidade sensorial. Segundo Vasconcellos, Cavalcanti e Barbosa (2002), na elaboração do cardápio deve-se dar destaque aos aspectos sensoriais, como combinação das preparações, tipo de alimentos e técnicas de processamento, cores, sabores e texturas.

Os altos índices de desperdício dessa unidade podem, provavelmente, sinalizar um problema de aceitação por parte do sabor dos alimentos. Para Ctenas e Vitolo (1999), os aspectos sensoriais, apresentação visual, cores e formatos atrativos e a forma de preparo dos alimentos, são cuidados que podem conduzir, de forma apropriada, a alimentação da criança. Assim, deve-se atentar às técnicas e tipos de preparações, preocupando-se com os gostos e hábitos das crianças, de modo a oferecer um preparo de refeições mais adequado a esse público.

Outro fator que pode ter contribuído para a grande porcentagem de desperdício foi o tamanho das porções servidas. Por se tratar de crianças, o tamanho da porção varia de acordo com cada faixa etária e os costumes alimentares da criança, o que dificulta a oferta de uma quantidade padrão para todas, levando, possivelmente, a um erro no porcionamento da refeição por parte dos funcionários.

Deve-se, ainda, levar em consideração que crianças mais velhas, naturalmente já buscam independência e fazem questão de se servirem sozinhas, podendo haver um erro maior no porcionamento e levando ao aumento de restos e, assim, ao desperdício dos alimentos, embora, segundo Holland (1999), em relação ao desenvolvimento de atitudes, como autonomia e iniciativa, o auto-serviço mostra-se um bom método. Quando a criança tem a oportunidade de escolher a quantidade de alimentos que ela irá comer, favorece o estabelecimento de auto-regulação, importante para formação de hábitos alimentares saudáveis.

Em casos, em que a criança é servida por outra pessoa, é preciso ficar atento a quais alimentos são deixados no prato e nos comentários das crianças para saber o verdadeiro motivo do baixo consumo e do alto índice de desperdício (FAQUIM; OLIVEIRA; SPINELLI, 2012). 


\section{CONCLUSÃO}

A quantidade de desperdício na UAN estudada foi considerada elevada. Observou-se que a quantidade de sobras e restos foi superior ao preconizado pela literatura.

Esses dados tornam necessária a estipulação de metas de desperdício, devendo-se observar a evolução dos restos, de forma a programar novos métodos, diminuindo, assim, as altas porcentagens do desperdício.

Recomenda-se uma melhor organização na distribuição das preparações dos cardápios, de forma que sejam menos repetitivos e mais adequados à faixa etária. É importante, também, que se implantem medidas educativas, tanto com atividades de educação nutricional para os alunos, quanto treinando para os funcionários da produção, alertando-os sobre a importância do preparo de refeições nutritivas, e aos sabores e técnicas mais adequados a esse público, de forma a propiciar uma aparência mais agradável, com pratos mais bonitos e coloridos.

Sugere-se, também, um controle do porcionamento, servindo menores quantidades de alimentos, monitorando o padrão de consumo de cada criança e adequando a quantidade de alimentos preparados a uma média do número de comensais em cada dia.

Possivelmente, essas medidas contribuam para aumentar o consumo, com uma melhor aceitação do cardápio e menor quantidade de sobras e restos.

\section{REFERÊNCIAS}

ABREU, E. S.; SPINELLI, M. G. N; SOUZA
PINTO, A. M. Gestão de Unidades de Alimentação e nutrição: um modo de fazer. 4. ed. São Paulo: Metha, 2011. 352p.

AKUTSU, R. C. et al. A ficha técnica de preparação como instrumento de qualidade na produção de refeições. Revista de Nutrição, Campinas, v. 18, n. 2, p. 277-279, 2005.

AMORIM, F. P.; GATTI, R. R. Avaliação do índice de resto-ingesta e sobras em unidade de alimentação e nutrição de escola estadual com regime de internato na cidade de Guarapuava - Paraná. 2010. Trabalho de conclusão de curso (Nutrição). Universidade Estadual do Centro-Oeste, Guarapuava, 2010.

BRADACZ, D. Modelo de gestão da qualidade para o controle de desperdício de alimentos em unidades de alimentação e nutrição. 2003. Dissertação (mestrado). Universidade Federal de Santa Catarina, Florianópolis, 2003.

CAMPOS, V.; VIANA, I.; ROCHA, A. Estudo de desperdícios alimentares em meio escolar. Nutr. pauta, v. 19, n. 109, p. 60-64, 2011.

CASTRO, M. D. S. et al. Resto-ingesta e aceitação de refeições em uma unidade de alimentação e nutrição. Higiene Alimentar, São Paulo, v. 17, n. 114/115, p. 24-28, 2003.

CTENAS M. L. B.; VITOLO, M. R. Crescendo com saúde: o guia de crescimento da criança. São Paulo: C2 Editora e Consultoria em Nutrição, 1999.

FAQUIM, N. B.; OLIVEIRA, T.; SPINELLI, M. G. N. Porcionamento, consumo e desperdício em um restaurante escolar. Revista Univap, São José dos Campos, v. 18, n. 31, jun. 2012. Disponível em: http://revista.univap.br/index.php/revistauniv 
ap/article/view/69. Acesso em: 14 ago. 2012. de Porto Alegre-RS. 2008. Trabalho de HOLLAND, C. V. A creche e seu papel na formação de práticas alimentares. 1999. Dissertação (mestrado). Faculdade de Saúde Pública, Universidade de São Paulo, São Paulo, 1999.

MAISTRO, L. Estudo do índice de resto ingestão em serviços de alimentação. Nutr.

Pauta, v.8, n.45, nov./dez. 2000. Disponível em:

http://www.nutricaoempauta.com.br/lista arti go.php?cod=123. Acesso em: 14 ago. 2012.

MULLER, P. Avaliação do desperdício de conclusão de Curso (nutrição). Universidade Federal do Rio Grande do Sul, 2008. Disponível

em:

http://www.lume.ufrgs.br/bitstream/handle/10 183/16556/000699412.pdf?sequence=1.

Acesso em: 14 ago. 2012.

VASCONCELLOS, F.; CAVALCANTI, E.; BARBOSA, L. Menu: como montar um cardápio eficiente. São Paulo: Roca, 2002.

VAZ, C. S. Restaurantes: Controlando custos e aumentando lucros. Brasília: LGE, 2006, 196p.

para os funcionários de um hospital público 